\title{
Isolation and Purification of Sesquiterpene Lactones from Ixeris sonchifolia (Bunge) Hance by High-Speed Counter- Current Chromatography and Semi-Preparative High Performance Liquid Chromatography
}

\author{
Wei Cai ${ }^{1}$, Jia Yu Zhang ${ }^{2}$, Guang Lei Li ${ }^{1}$, Guo Ping Chang ${ }^{1}$, Ya Lei Wei ${ }^{1}$, Hong \\ Gui Zhang ${ }^{1 *}$ and Jian Qiu Lu ${ }^{2 *}$ \\ ${ }^{1}$ School of Chinese Pharmacy, Beijing University of Chinese Medicine, Beijing 100102, ${ }^{2}$ Center of Scientific Experiment, Beijing \\ University of Chinese Medicine, Beijing 100029, China
}

*For correspondence: Email: bzy714@163.com, lujq@vip.sina.com; Tel: +86 10 84738642; Fax: +86 1084738642

Received: 9 July 2014

Revised accepted: 5 November 2014

\begin{abstract}
Purpose: To isolate and purify sesquiterpene lactones from Ixeris sonchifolia (Bunge) Hance by highspeed counter-current chromatography (HSCCC).

Methods: I. sonchifolia was extracted with water and then loaded on a glass column $(10 \times 1500 \mathrm{~cm}$ containing $3000 \mathrm{~g} D 101$ macroporous resin) where various concentrations of aqueous ethanol $(0,10,30$, 50 , and $95 \%)$ were used to elute the column successively. The $50 \%$ ethanol fraction was purified by HSCCC using a solvent system comprised of ethyl acetate: $n$-butanol: methanol: water (4: 6: 1: 20, v/v), and semi-preparative high performance liquid chromatography (HPLC). The chemical structures of the components obtained were further confirmed by high-resolution mass spectroscopy (MS) and nuclear magnetic resonance spectroscopy (NMR).

Results: Three compounds, including ixerin Z1 (0.7 mg), ixerin Z (11.4 mg), and 11, 13a-dihydroixerin Z $(8.2 \mathrm{mg})$, with purity of $96.2,98.2$, and $98.4 \%$, respectively, were obtained from $200 \mathrm{mg}$ each of the 50 $\%$ ethanol fraction.

Conclusion: HSCCC is a rapid and effective method for isolating and purifying sesquiterpene lactones from I. sonchifolia.
\end{abstract}

Keywords: Sesquiterpene lactones, High-speed counter-current chromatography, Ixeris sonchifolia, Ixerin, 13a-Dihydroixerin

\begin{abstract}
Tropical Journal of Pharmaceutical Research is indexed by Science Citation Index (SciSearch), Scopus, International Pharmaceutical Abstract, Chemical Abstracts, Embase, Index Copernicus, EBSCO, African Index Medicus, JournalSeek, Journal Citation Reports/Science Edition, Directory of Open Access Journals
\end{abstract} (DOAJ), African Journal Online, Bioline International, Open-J-Gate and Pharmacy Abstracts

\section{INTRODUCTION}

Ixeris sonchifolia (Bunge) Hance, commonly called kudiezi in China, which belongs to the family Compositae, is mainly distributed in Northeastern areas of China [1]. It is widely used as a folk medicine in China for its remarkable medical effects, such as dissipating blood stasis, improving microcirculation, and antineoplastic activity [2-5].
The chemical compounds of this plant are sesquiterpene lactones, organic acids, flavonoids, and triterpenes [6-9]. Ixerin $Z$ and $11,13 \alpha$-dihydroixerin $Z$ are the major sesquiterpene lactones [10], which have been reported to have various activities for instance, anti-inflammatory, anti-microbial, and anti-tumor activities [11,12]. In order to gain enough reference substance to perform further 
investigation on its metabolism, it is important to use an efficient method to isolate and purify ixerin $Z$ and 11,13 a-dihydroixerin $Z$ from their natural sources.

Some conventional techniques including silica gel column chromatography have been successfully used to separate these chemicals from this plant [10]. However, these classic chromatography methods are complicated, inefficient, and time-consuming. Thus, an efficient and low-cost technique to obtain these compounds is required.

In the past few years, high-speed counter-current chromatography (HSCCC), a support-free liquidliquid partition chromatographic technique, has been reported to eliminate irreversible adsorption of sample onto solid support matrix, stationaryphase deactivation, and contamination, and has made great progress in preparative isolation and purification of active components from natural products [13-15]. Therefore, our aim is to establish a protocol for enriching and isolating sesquiterpene lactones effectively from $l$. sonchifolia by HSCCC and to provide enough reference substance for in vitro and in vivo studies.

\section{EXPERIMENTAL}

\section{Apparatus}

The instrument used was a TBE-300B HSCCC (Tauto Biotech, Shanghai, China) equipped with three multi-layer coil separation columns connected in series (total volume of $300 \mathrm{~mL}$ ) and a $20 \mathrm{~mL}$ sample loop. The $\beta$ value of the preparative column varied from 0.5 at the internal layer to 0.8 at the external layer. The revolution speed of the apparatus was regulated with a speed controller in the range from 0 to $1000 \mathrm{rpm}$. The HSCCC system was equipped with a TBP1002 pump (Aglient, Santa Clara, USA), an HX1050 constant temperature regulator (Beijing Boyikang Lab Implement, Beijing, China), a TBD2000 UV detector (Aglient, Santa Clara, USA) operating at $254 \mathrm{~nm}$.

The analytical TBE-20A HSCCC instrument (Tauto Biotech, Shanghai, China) used was equipped with three polytetrafluoroethylene preparative coils (diameter of tube, $0.8 \mathrm{~mm}$; total volume, $16 \mathrm{~mL}$ ). The $\beta$ value varied from 0.6 at the internal terminal to 0.78 at the external terminal.

HPLC analysis was performed on an Agilent system equipped with ultraviolet detector
(Agilent, Santa Clara, USA). The MS analyses were performed with a LTQ-Orbitrap coupled with an ESI source (Thermo Electron, Bremen, Germany). The structures of the compounds were identified by Bruker Avance 500 NMR (Bruker Biospin, Rheinstetten, Germany).

\section{Reagents and materials}

I. sonchifolia was collected from Haicheng city, Liaoning province of China in September 2013. It was authenticated by Professor Jian-Qiu Lu, Center of Scientific Experiment, Beijing University of Chinese Medicine. A voucher specimen (no. 20130901) was deposited in the same department. All organic solvents used for HSCCC separation were of analytical grade (Beijing chemicals works, Beijing, China). Acetonitrile used for HPLC was of HPLC grade (Fisher, NJ, USA), and water was prepared by a Milli-Q water purification system (Millipore, Billerica, MA, USA) in our laboratory. D101 macroporous resin was purchased from the Chemical Plant of Nankai University (Tianjin, China).

\section{Preparation of crude extract}

The whole herb of $I$. sonchifolia $(2 \mathrm{~kg})$ was chopped and extracted with $12 \mathrm{~L}$ pure water by refluxing for $1 \mathrm{~h}$, which was repeated three times. The extract was loaded on a glass column $(10 \times$ $1500 \mathrm{~cm}$ ) containing $3000 \mathrm{~g} \mathrm{D101}$ macroporous resin. Various concentrations of aqueous ethanol $(0,10,30,50$, and $95 \%)$ were used to elute the column successively. The $50 \%$ ethanol fraction was concentrated under reduced pressure to achieve a brown residue.

\section{HSCCC separation and semi-preparative HPLC purification procedures}

During HSCCC separation, a two-phase solvent system of ethyl acetate n-butanol methanol water $(4: 6: 1: 20, \mathrm{v} / \mathrm{v})$ was chosen to separate the compounds. The multilayer coil column was first completely filled with the upper phase as the stationary phase, and the lower phase was then pumped into the head end of the inlet column at a flow rate of $2.0 \mathrm{~mL} / \mathrm{min}$, while the apparatus was rotated at $900 \mathrm{rpm}$. After hydrodynamic equilibrium was established throughout the coil, as indicated by a clear mobile phase eluting at the tail outlet, the sample solution $(200 \mathrm{mg}$ of the $50 \%$ ethanol fraction in solvent composed of 10 $\mathrm{mL}$ the lower and $10 \mathrm{~mL}$ upper phases) was injected into the column through the sample loop. During the separation process, the column temperature was set at $30{ }^{\circ} \mathrm{C}$. The detection wavelength was $254 \mathrm{~nm}$. The effluent was 
continuously monitored and the fractions were collected according to the chromatograms obtained.

HPLC analysis and identification of compounds The $50 \%$ ethanol fraction and each peak fraction from HSCCC were all analyzed by HPLC using a Zorbax SB-C18 column $(5 \mu \mathrm{m}, 250 \times 4.6 \mathrm{~mm}$, Agilent Technologies, Germany). A linear gradient elution of solvent water (A) and acetonitrile (B) was applied with the following program: $0-10 \mathrm{~min}, 5-15 \% \mathrm{~B} ; 10-25 \mathrm{~min}, 15$ - $20 \%$ B; 25 - 35 min, $20-25 \%$ B; $35-45$ min, $25-30 \%$ B; $45-60$ min, $30-55 \%$ B; 60 $-75 \mathrm{~min}, 55-100 \% \mathrm{~B}$. The flow rate was 1.0 $\mathrm{mL} / \mathrm{min}$ and the column temperature was at room temperature. The effluents were monitored at $254 \mathrm{~nm}$ by a UV detector.

The chemical structures of compounds separated by HSCCC were all analyzed by LTQOrbitrap coupled with an ESI source in flowinjection mode. The optimized operating parameters in the negative ion mode were as follows: capillary voltage of $35 \mathrm{~V}$, capillary temperature of $350{ }^{\circ} \mathrm{C}$, electrospray voltage of $3.0 \mathrm{kV}$, sheath gas flow rate of 30 (arbitrary units), auxiliary gas flow rate of 10 (arbitrary units), and tube lens of $110 \mathrm{~V}$.

\section{RESULTS}

Under the HSCCC conditions, fractions A and B were separated from sample in a single HSCCC step (shown in Figure 1) within $240 \mathrm{~min}$. The purities of compound 1 in fractions A was $79.5 \%$ based on HPLC peak area percentage. After crystallization with dichloromethane, compound 1 with higher purity was obtained from fractions $A$. Fraction B was a mixture of two compounds, which was further purified on semi-preparative HPLC using acetonitrile water $(17: 83, v / v)$ at 2.0 $\mathrm{mL} / \mathrm{min}$ to yield compounds 2 and 3 .

The chemical structures of compounds separated by HSCCC were identified according to the HRMS, H-NMR, and C-NMR data. Their chemical structures are displayed in Figure 2. The quantity and purity of the three compounds are shown in Table 1.

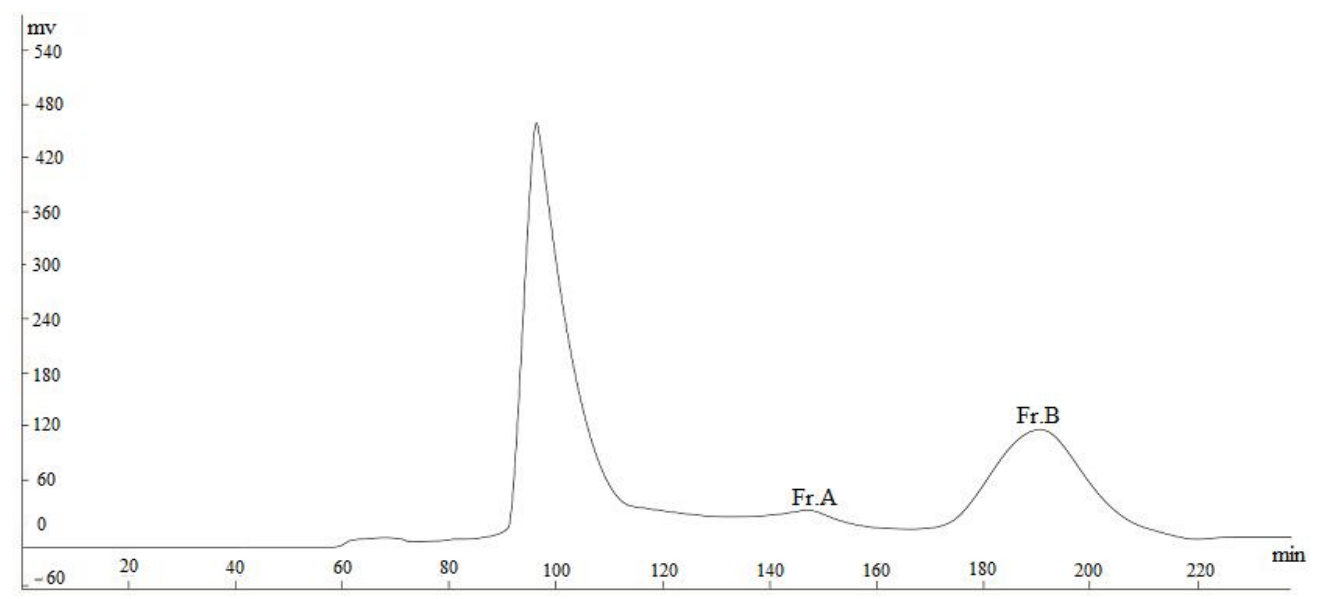

Figure 1: HSCCC chromatogram of crude extract of Ixeris sonchifolia<smiles>C=C1C(=O)OC2C1CCC(C)=C1C(=O)C(OC3OCC(O)C(O)C(O)C3O)=C(C)C12</smiles>

1<smiles>C=C1C(=O)OC2C1CCC(C)=C1C(=O)C(OC(O)CCOCC(O)CO)=C(C)C12</smiles>

2<smiles>CC1=C2C(=O)C(OC(O)C(CO)CO)=C(C)C2C2OC(=O)C(C)C2CCC1C</smiles>

3

Figure 2: Chemical structures of isolated sesquiterpene lactones 
Table 1: Quantity and purity of isolated compounds

\begin{tabular}{lcc}
\hline Compounds & Content (mg/g) & Purity (\%) \\
\hline Ixerin Z1 & 3.5 & 96.2 \\
Ixerin Z & 57 & 98.2 \\
11,13a-dihydroixerin Z & 41 & 98.4 \\
\hline
\end{tabular}

Compound 1: ESI-MS (m/z): $555.1865[\mathrm{M}-\mathrm{H}]$ (0.74 ppm, $\left.\mathrm{C}_{29} \mathrm{H}_{31} \mathrm{O}_{11}\right)$. ${ }^{1} \mathrm{H}-\mathrm{NMR}(500 \mathrm{MHz}$, $\left.\mathrm{C}_{5} \mathrm{D}_{5} \mathrm{~N}\right)$ ठ: $3.30(1 \mathrm{H}, \mathrm{m}, \mathrm{H}-5), 3.29(1 \mathrm{H}, \mathrm{m}, \mathrm{H}-6)$, $2.76(1 \mathrm{H}, \mathrm{m}, \mathrm{H}-7), 1.89(1 \mathrm{H}, \mathrm{m}, \mathrm{H}-8), 1.12(1 \mathrm{H}$, $\mathrm{m}, \mathrm{H}-8), 2.30(1 \mathrm{H}, \mathrm{t}, \mathrm{H}-9), 2.10(1 \mathrm{H}, \mathrm{m}, \mathrm{H}-9), 6.18$ $(1 \mathrm{H}, \mathrm{d}, \mathrm{J}=3.2 \mathrm{~Hz}, \mathrm{H}-13), 5.35(1 \mathrm{H}, \mathrm{d}, \mathrm{J}=2.7 \mathrm{~Hz}$, $\mathrm{H}-13), 2.50(3 \mathrm{H}, \mathrm{s}, \mathrm{H}-14), 2.35(3 \mathrm{H}, \mathrm{s}, \mathrm{H}-15)$, $6.15\left(1 \mathrm{H}, \mathrm{d}, \mathrm{J}=7.8 \mathrm{~Hz}, \mathrm{H}-1^{\prime}\right), 4.23\left(1 \mathrm{H}, \mathrm{m}, \mathrm{H}-2^{\prime}\right)$, $4.30\left(1 \mathrm{H}, \mathrm{m}, \mathrm{H}-3^{\prime}\right), 4.17\left(1 \mathrm{H}, \mathrm{m}, \mathrm{H}-4^{\prime}\right), 4.13(1 \mathrm{H}$, m, H-5'), $5.02\left(1 \mathrm{H}, \mathrm{m}, \mathrm{H}-6^{\prime}\right), 4.76\left(1 \mathrm{H}, \mathrm{dd}, \mathrm{H}-6^{\prime}\right)$, $3.72(2 \mathrm{H}, \mathrm{d}, \mathrm{J}=4.8 \mathrm{~Hz}, \mathrm{H}-2$ "), $7.33(2 \mathrm{H}, \mathrm{d}, \mathrm{J}=$ $\left.8.4 \mathrm{~Hz}, \mathrm{H}-4,8^{\prime}\right), 7.13\left(2 \mathrm{H}, \mathrm{d}, \mathrm{J}=8.4 \mathrm{~Hz}, \mathrm{H}-5^{\prime}\right.$, 7'); ${ }^{13} \mathrm{C}-\mathrm{NMR}\left(125 \mathrm{MHz}, \mathrm{C}_{5} \mathrm{D}_{5} \mathrm{~N}\right)$ ס: 129.7 (C-1), 189.1 (C-2), 153.8 (C-3), 147.2 (C-4), 48.0 (C-5), 85.2 (C-6), 52.5 (C-7), 25.2 (C-8), 37.0 (C-9), 153.1 (C-10), 139.6 (C-11), 169.1 (C-12), 118.0 (C-13), 21.7 (C-14), 15.0 (C-15), 102.0 (C-1'), 75.3 (C-2'), 78.1 (C-3'), 71.2 (C-4'), 75.7 (C-5'), 64.7 (C-6'), 172.1 (C-1"), 40.3 (C-2"), 125.2 (C3"), 131.0 (C-4"), 116.2 (C-5"), 157.9 (C-6"), 116.2 (C-7"), 131.0 (C-8"). These data are in good agreement with those of ixerin Z1 [16].

Compound 2: ESI-MS $(\mathrm{m} / \mathrm{z}): 421.1506[\mathrm{M}-\mathrm{H}]$ (3.07 ppm, $\left.\mathrm{C}_{21} \mathrm{H}_{25} \mathrm{O}_{9}\right)$. ${ }^{1} \mathrm{H}-\mathrm{NMR}(500 \mathrm{MHz}$, $\left.\mathrm{CD}_{3} \mathrm{OD}\right) \delta: 3.58(1 \mathrm{H}, \mathrm{d}, \mathrm{H}-5), 3.62(1 \mathrm{H}, \mathrm{m}, \mathrm{H}-6)$, $3.04(1 \mathrm{H}$, brt, $\mathrm{H}-7), 2.27(1 \mathrm{H}, \mathrm{m}, \mathrm{H}-8), 1.42(1 \mathrm{H}$, d, H-8), $2.63(1 \mathrm{H}, \mathrm{t}, \mathrm{H}-9), 2.42(1 \mathrm{H}, \mathrm{m}, \mathrm{H}-9), 5.56$ $(1 \mathrm{H}, \mathrm{d}, \mathrm{J}=3.3 \mathrm{~Hz}, \mathrm{H}-13), 6.09(1 \mathrm{H}, \mathrm{d}, \mathrm{J}=3.3 \mathrm{~Hz}$, $\mathrm{H}-13), 2.44(3 \mathrm{H}, \mathrm{s}, \mathrm{H}-14), 2.26(3 \mathrm{H}, \mathrm{s}, \mathrm{H}-15)$, $5.23\left(1 \mathrm{H}, \mathrm{d}, \mathrm{J}=7.6 \mathrm{~Hz}, \mathrm{H}-1^{\prime}\right), 3.34\left(1 \mathrm{H}, \mathrm{m}, \mathrm{H}-2^{\prime}\right)$, $3.41\left(1 \mathrm{H}, \mathrm{m}, \mathrm{H}-3^{\prime}\right), 3.36\left(1 \mathrm{H}, \mathrm{m}, \mathrm{H}-4^{\prime}\right), 3.39(1 \mathrm{H}$, m, H-5'), $3.82\left(1 \mathrm{H}, \mathrm{dd}, \mathrm{H}-6^{\prime}\right), 3.69\left(1 \mathrm{H}, \mathrm{d}, \mathrm{H}-6^{\prime}\right)$; ${ }^{13} \mathrm{C}-\mathrm{NMR}\left(125 \mathrm{MHz}, \mathrm{CD}_{3} \mathrm{OD}\right) \mathrm{\delta}$ : 130.6 (C-1), 191.1 (C-2), 154.5 (C-3), 150.1 (C-4), 53.8 (C-5), 87.1 (C-6), 49.4 (C-7), 25.4 (C-8), 38.1 (C-9), 156.2 (C-10), 140.7 (C-11), 171.3 (C-12), 119.2 (C-13), 22.4 (C-14), 15.4 (C-15), 102.5 (C-1'), 75.5 (C-2'), 78.4 (C-3'), 71.4 (C-4'), 78.0 (C-5'), $62.6\left(\mathrm{C}-6^{\prime}\right)$. These data are in good agreement with those of ixerin Z [17].

Compound 3: ESI-MS (m/z): $423.1666[\mathrm{M}-\mathrm{H}]$ (3.88 ppm, $\left.\mathrm{C}_{21} \mathrm{H}_{27} \mathrm{O}_{9}\right)$. ${ }^{1} \mathrm{H}-\mathrm{NMR} \quad(500 \mathrm{MHz}$, $\left.\mathrm{CD}_{3} \mathrm{OD}\right) \delta: 3.47(1 \mathrm{H}, \mathrm{d}, \mathrm{H}-5), 3.66(1 \mathrm{H}, \mathrm{m}, \mathrm{H}-6)$, $2.09(1 \mathrm{H}$, brt, $\mathrm{H}-7), 2.02(1 \mathrm{H}, \mathrm{m}, \mathrm{H}-8), 1.37(1 \mathrm{H}$, $\mathrm{d}, \mathrm{H}-8), 2.55(1 \mathrm{H}, \mathrm{t}, \mathrm{H}-9), 2.35(1 \mathrm{H}, \mathrm{m}, \mathrm{H}-9), 2.06$ $(1 \mathrm{H}, \mathrm{d}, \mathrm{H}-11), 1.22(3 \mathrm{H}, \mathrm{d}, \mathrm{J}=6.9 \mathrm{~Hz}, \mathrm{H}-13)$, $2.44(3 \mathrm{H}, \mathrm{s}, \mathrm{H}-14), 2.23(3 \mathrm{H}, \mathrm{s}, \mathrm{H}-15), 5.22(1 \mathrm{H}$, $\left.\mathrm{d}, \mathrm{J}=6.9 \mathrm{~Hz}, \mathrm{H}-1^{\prime}\right), 3.41\left(1 \mathrm{H}, \mathrm{m}, \mathrm{H}-2^{\prime}\right), 3.31(1 \mathrm{H}$, $\left.\mathrm{m}, \mathrm{H}-3^{\prime}\right), 3.36\left(1 \mathrm{H}, \mathrm{m}, \mathrm{H}-4^{\prime}\right), 3.39\left(1 \mathrm{H}, \mathrm{m}, \mathrm{H}-5^{\prime}\right)$, $3.83\left(1 \mathrm{H}, \mathrm{dd}, \mathrm{H}-6^{\prime}\right), 3.69\left(1 \mathrm{H}, \mathrm{d}, \mathrm{H}-6^{\prime}\right) ;{ }^{13} \mathrm{C}-\mathrm{NMR}$

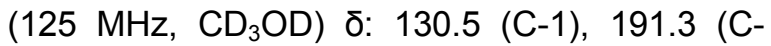
2), 154.4 (C-3), 150.8 (C-4), 49.0 (C-5), 86.8 (C6), 57.1 (C-7), 26.9 (C-8), 38.4 (C-9), 156.4 (C10), 42.2 (C-11), 180.3 (C-12), 12.6 (C-13), 22.2 (C-14), 15.4 (C-15), 102.6 (C-1'), 75.5 (C-2'), 78.4 (C-3'), 71.4 (C-4'), 78.0 (C-5'), 62.6 (C-6'). These data are in good agreement with those of 11,13a-dihydroixerin Z [18].

\section{DISCUSSION}

An HPLC method for the determination of the purities of sesquiterpene lactones separated by HSCCC was established at first. In order to obtain an appropriate elution system, mobile systems such as methanol water and acetonitrile water were tested. The result demonstrated that acetonitrile water with a gradient elution mode could afford better resolution of chromatographic peaks among the targets and the other compounds.

The important step in the successful separation of HSCCC is the selection of suitable two-phase solvent system [19]. In our experiments, $n$ butanol methanol water at different volume ratios were first selected as solvent system [20], and tested by analytical HSCCC. The analytes were eluted close to the solvent front with poor separation, whereas an addition of ethyl acetate could yield a suitable separation time and a much better resolution.

Due to the similar structures and largely polarities of ixerin Z and 11,13a-dihydroixerin Z, it is difficult to separate them from complex system in a single HSCCC procedure with these two-phase solvent systems [21]. Thus semipreparative HPLC was chosen to isolate and purify the mixture of ixerin $Z$ and $11,13 \alpha-$ dihydroixerin Z.

\section{CONCLUSION}

A rapid and effective method for the isolation and purification of the major sesquiterpene lactones from I. sonchifolia, which could provide reference substances for further metabolism studies, is reported in this work. To the best of our knowledge, this is the first report on separation of sesquiterpene lactones in medical plants using HSCCC method. 


\section{ACKNOWLEDGEMENT}

This work was supported by National Basic Research and Development Program of China (973 Program, no. 2012CB518406).

\section{REFERENCES}

1. Nanjing University of Chinese Medicine. Encyclopedia of Chinese Materia Medica, vol.2. Shanghai Science and Technology Press, Shanghai, China; 2006; pp 1783-1785.

2. Chen CG, Jia HL, Lv SX, Xu CQ. Protective effect of Kudiezi on acute cerebral ischemic reperfusion injury in rats. Chin J Clin Pharmacol 2012; 28: 196-199.

3. Lin $Y, H u S, X u D$, Zheng $G$. Vasodilation effect of water extract from Ixeris sonchifolia (Bge.) Hance in rat thoracic aortic rings in vitro. Chin J Pharmacol Toxicol 2007; 21: 202-206.

4. Su BY, Jung HL, Hae YC, Kwang SI, Song JB, Jae SC, Nam DK. Inhibitory effects of luteolin isolated from ixeris sonchifolia hance on the proliferation of hepg2 human hepatocellular carcinoma cells. Arch Pharmacal Res 2003; 26(2): 151-156.

5. Fukumoto LR, Mazza G. Assessing antioxidant and prooxidant activities of phenolic compounds. J Agric Food Chem 2000; 48(8): 3597-3604.

6. Zhang WZ, Li XL, Wang MJ, Shi LG, Zhao DF, Zhang SJ. Sesquiterpene lactones from Ixeris sonchifolia (Bge.) Hance. J Asian Nat Prod Res 2008; 10(8): 753-758.

7. Shi P, Zhang Y, Qu H, Fan X. Systematic haracterization of secondary metabolites from Ixeris sonchifolia by the combined use of HPLC-TOFMS and HPLC-ITMS. Phytochem Anal 2011; 22(1): 66-73.

8. Feng XZ, Dong $M$, Gao ZJ, Xu SX. Three new triterpenoid saponins from Ixeris sonchifolia and their cytotoxic activity. Planta Med 2003; 69(11): 10361040.

9. Liu Y, Lu JQ, Zhang JY, Wang Q, Wang F, Qiao YJ, Zhang YL. Rapid determination of ten polyphenols in Kudiezi injection using ultra-performance liquid chromatography-tandem mass spectrometry in multiple reaction monitoring mode. Anal Methods 2012; 4: 4230-4236.
10. Ni R. Preparation of active sesquiterpene lactone glucosides from Ixeris sonchifolia (Bge.) Hance and studies on their biotransfomation [dissertation]. [Shenyang]: Shenyang Pharmaceutical University, 2006; $p 32$.

11. Zhang $Y C$, Zhou $L, N g K Y$. Sesquiterpene lactones from Ixeris sonchifolia Hance and their cytotoxicities on A549 human non-small cell lung cancer cells. J Asian Nat Prod Res 2009; 11(4): 294-298.

12. Suh J, Jo Y, Kim ND, Bae SJ, Jung JH, Im KS. Cytotoxic constituents of the leaves of Ixeris sonchifolia. Arch Pharm Res 2002; 25: 289-292.

13. Degenhardt A, Knapp $H$, Winterhalter $P$. Rapid isolation of malvidin 3-glucoside from red wine by high speed countercurrent chromatography (HSCCC). Vitis 2000; 39(1): 43-44.

14. Yang $Y$, Huang $Y, G u$, Yili A, Sabir G, Aisa H. A. Separation and purification of three flavonoids from Helichrysum arenarium (L.) Moench by HSCCC. Chromatographia 2009; 69(9/10): 963-967.

15. Du Q, Yuan J. Preparation of triterpene saponins from the fruit of momordica charantia $L$. by high speed countercurrent chromatography (HSCCC). J Liq Chromatogr R T 2005; 28(11): 1717-1724.

16. Feng $X Z, X u S X$, Dong M. A new sesquiterpene lactone glucoside from Ixeris sonchifolia. J Asian Nat Prod Res 2001; 3(4): 247-251.

17. Ma JY, Wang ZT, Xu LS, Xu GJ, Kadota S, Namba $T$. Sesquiterpene lactones from Ixeris sonchifolia. Phytochemistry 1998; 48(1): 201-203.

18. Na Z, Cho JY, Lee HJ, Chung JH, Park KD, Lee YJ, Shin SC, Rim YS, Park HK, Moon JH. Complete $1 \mathrm{H}$ and 13C NMR assignments of sesquiterpene glucosides from Ixeris sonchifolia. Magn Reson Chem 2007; 45(3): 275-278.

19. Guzlek H, Wood PL, Janaway L. Performance comparison using the guess mixture to evaluate counter-current chromatography instruments. J Chromatogr A 2009; 1216: 4181-4186.

20. Cao XL. High-Speed Counter-Current Chromatography and its Application, Chemistry Industry Press, Beijing, China; 2005; $p 55$

21. Su W, Liu Q, Yang Q, Yu JG, Chen XQ. Separation and purification of four compounds from Desmodium styracifolium using off-line two-dimensional highspeed counter-current chromatography. J. Sep. Sci 2013; 36: 3338-3344 